\title{
CORRECTION
}

\section{Correction to: Optimization for coproduction of protease and cellulase from Bacillus subtilis M-11 by the Box-Behnken design and their detergent compatibility}

Sercan Özbek Yazıcı' ${ }^{1}$ Ismail Özmen²

Published online: 20 June 2020

(c) Associação Brasileira de Engenharia Química 2020

\author{
Correction to: \\ Brazilian Journal of Chemical Engineering \\ (2020) 37:49-59 \\ https://doi.org/10.1007/s43153-020-00025-x
}

Dear readers,

The authors found a mistake in Figs. 1 and 2 of this published paper.

The corrected Figs. 1 and 2 are presented below.

The authors apologize for these mistakes.

The original article can be found online at https://doi.org/10.1007/ s43153-020-00025-x.

Sercan Özbek Yazıcı

sozbekyazici@hotmail.com

Ismail Özmen

ismailozmen@sdu.edu.tr

1 Mehmet Akif Ersoy University Burdur, 15100 Burdur,

Turkey

2 Suleyman Demirel Universitesi, Isparta, Turkey 

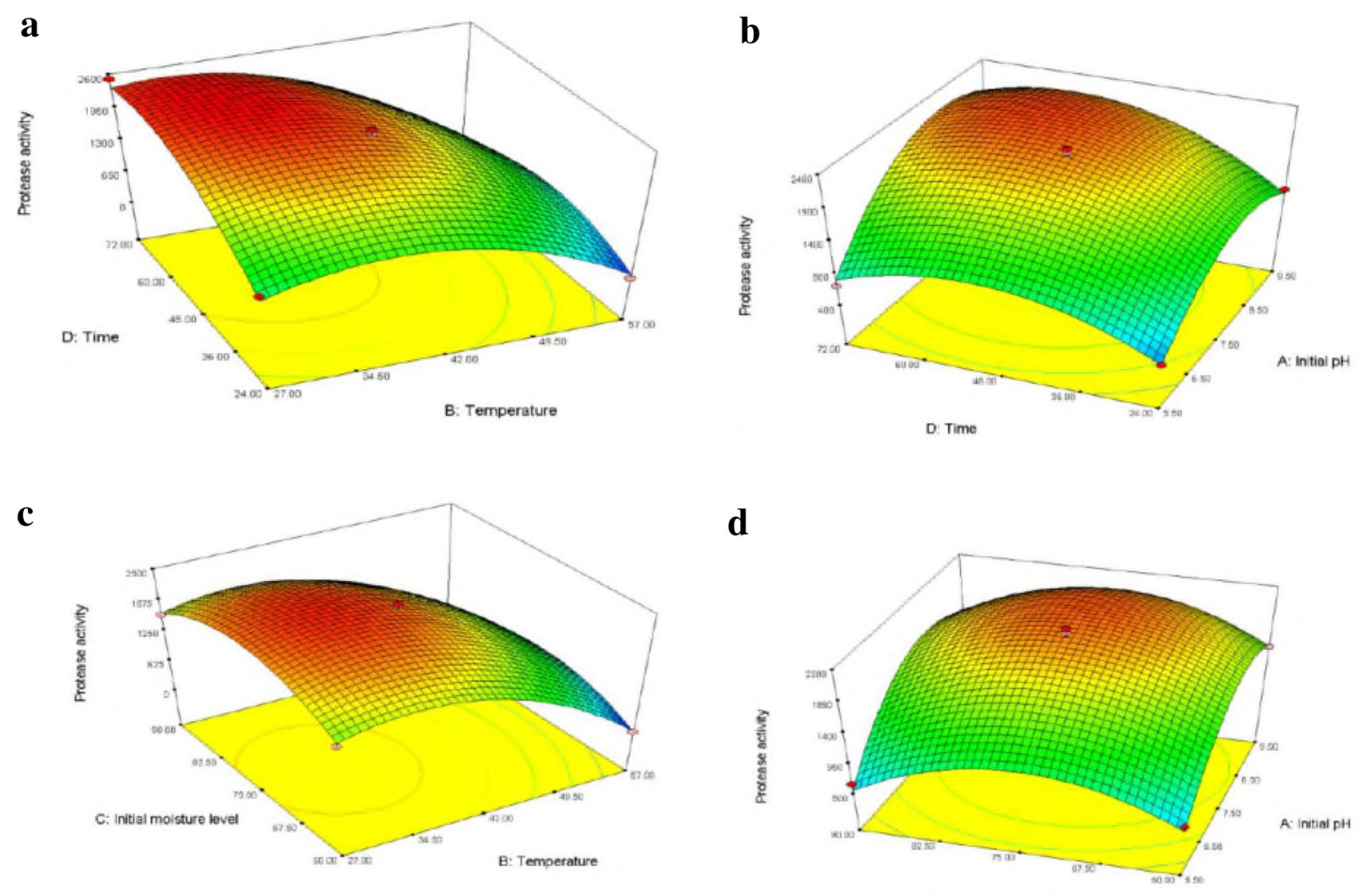

e
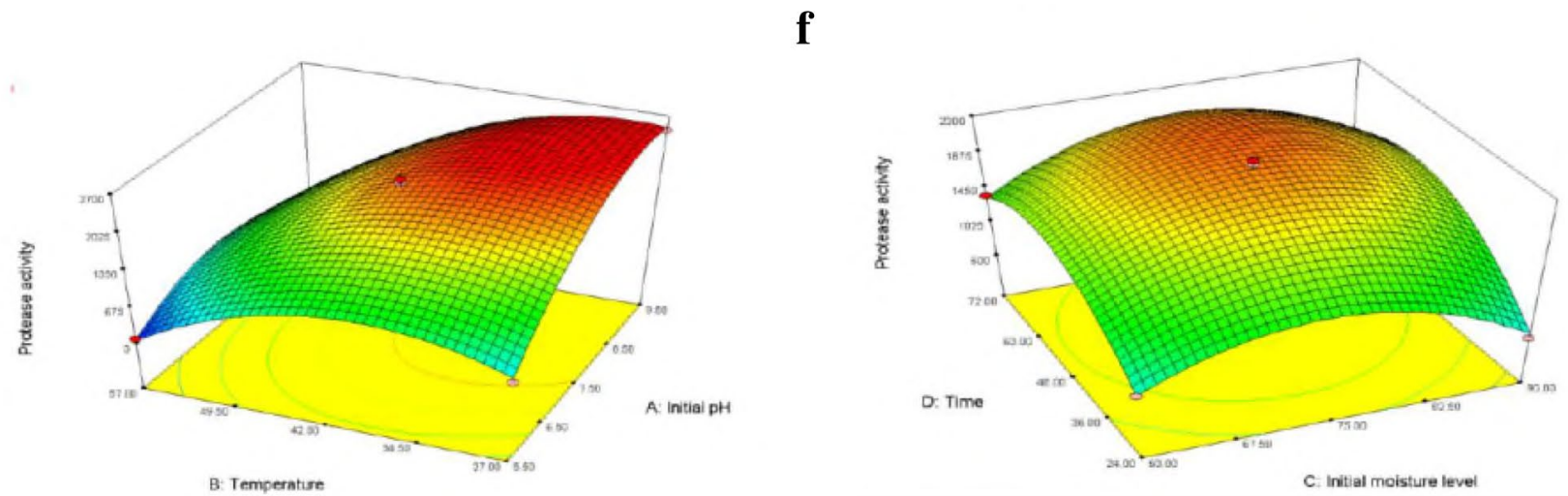

Fig. 13 -D plots of the combined effects of two variables on protease production 

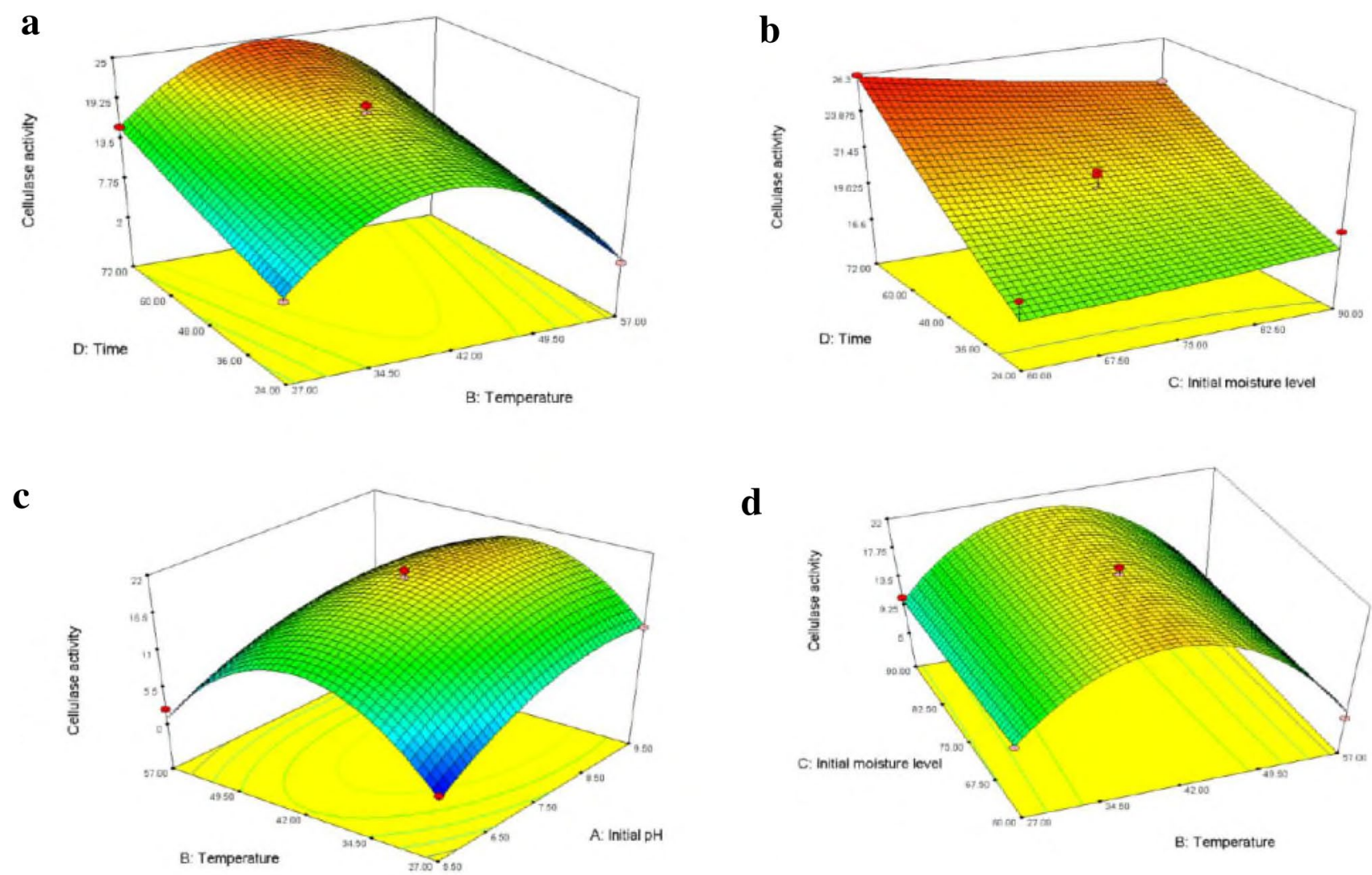

d

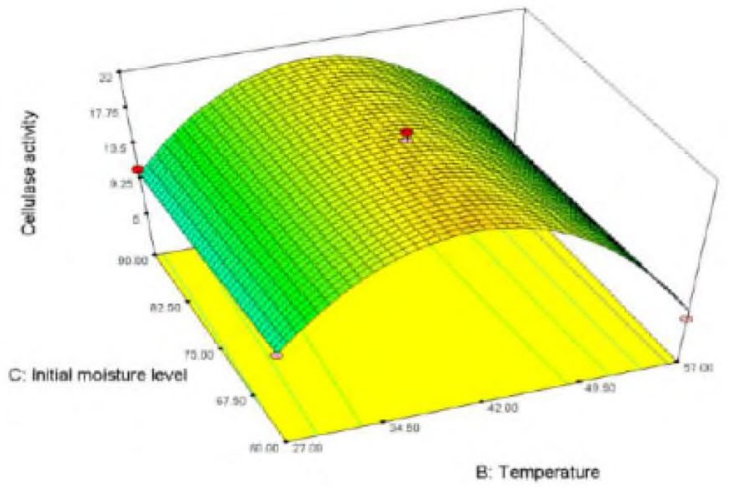

$\mathbf{e}$

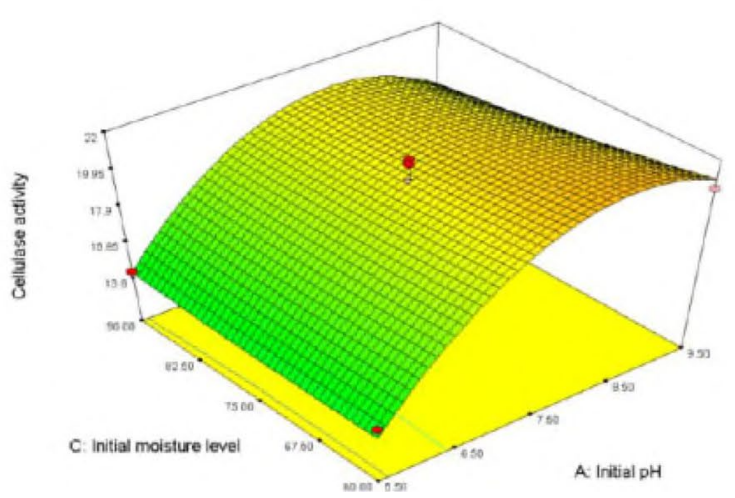

f

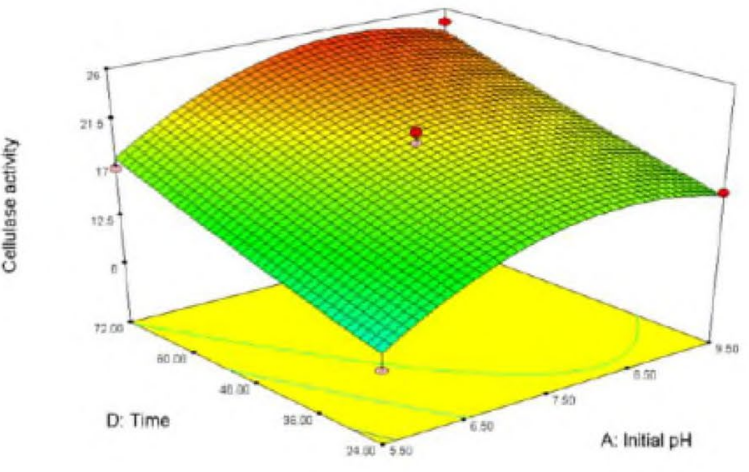

Fig. 2 3-D plots of the combined effects of two variables on cellulase production 